\title{
Tear Shape
}

National Cancer Institute

\section{Source}

National Cancer Institute. Tear Shape. NCI Thesaurus. Code C48351.

The stylized shape of a tear or drop of water. It differs from an oval because one end is clearly larger than the other. It is synonymous with the shapes egg, pear, and almond. See also oval. 